\title{
Strain differences in neophilia in the rat
}

\author{
GORDON M. HARRINGTON \\ University of Northern Iowa, Cedar Falls, Iowa 50613
}

\begin{abstract}
Latencies to approach a novel physical object and a novel human hand placed in the home cage were obtained for 599 rats from 12 inbred strains: ACI, A990, A35322, F344, INR, IR, MNR/Har, MNRA, MR/Har, TS1, TS3, WAG. Comparison with results of other studies of these strains show consistencies among different measures of exploratory behavior where differences might have been expected. The results also provide parametric data for methodological use and add to the standardization of these strains as behaviorally defined lines.
\end{abstract}

In the first systematic use of the rat in psychological research, Small $(1899,1900)$ respectively identified "curiosity" and "timidity" as independent "intellectual" and "emotional" "traits." By "curiosity," he meant exploratory behavior. From factor analysis of data based on Hall's (1938) lines of rats, Billingslea (1940, $1941,1942)$ suggested that exploratory behavior and response inhibition to novel objects constituted a single factor of "emotionality." However, while wild rats and laboratory rats are similar in exploratory behavior in both familiar and strange environments, there are striking differences between the two in response to novel objects in a familiar environment. There is striking response inhibition or avoidance (neophobia) in the wild rat, whereas there may even be an increment in exploration (neophilia) in the laboratory species. It would appear to many that such response inhibition is independent of general exploratory behavior and that it has been bred out of the laboratory animal (Barnett, 1975). If indeed this is a heritable characteristic, then it may prove useful to examine genetic variation in response to novel objects. In the present study, strain differences in approach to a novel animate object and to a novel inanimate object in the animal's home cage environment were examined for those 12 genetically defined lines of rats having the highest frequency of citation in the behavioral literature. This is one of a number of studies (Harrington, 1971a, 1971b, 1972, 1979a, 1979b, 1979c, 1979d, 1979e, 1979f, 1979g, 1979h, 1979i; Harrington \& Hellwig, 1979a, 1979b) intended to provide behavioral standardization data for those strains. The study is thus motivated in part by the general interdisciplinary concern in recent years for precise specification and standardization of lines of laboratory animals (International Committee on Laboratory Animals, 1971).

\section{METHOD}

\section{Subjects}

Subjects were 599 rats aged 68-74 days, with a minimum of 20 animals of each sex within each of the following 12 inbred strains: ACI/Har, A990/Har, A35322/Har, F344/DuHar, INR, IR, MNR/Har, MNRA (formerly MNR-a/Har), MR/Har, TS1, TS3, and WAG/Har. All lines are designated by the standard nomenclature for this species and are described in the fourth international listing (Festing \& Staats, 1973). Animals were bred and maintained at $25.5^{\circ} \mathrm{C} \pm 1.1^{\circ} \mathrm{C}$ and $40 \% \pm 5 \%$ relative humidity. Breeders and pups were housed under a natural light cycle. Pups were handled for $1 \mathrm{~min}$ on alternate days from age 14 to 45 days. At 45 days they were transferred to individual Wahmann LC75-A cages with 24-h light cycle. Maintenance was in a primary animal colony space with normal animal caretaking activities. More detailed descriptions are available elsewhere (Harrington, 1968).

\section{Apparatus and Procedure}

An experimenter who had not had previous contact with the animal opened the cage $10 \mathrm{~cm}$ and waited for the animal to settle, as evidenced by the top of the animal's head being raised above the top of the cage. The experimenter then placed a clenched fist into the cage approximately $5 \mathrm{~cm}$ and timed the latency to approach and sniff the hand. The experimenter then inserted a vertical panel parallel to the front of the cage $10 \mathrm{~cm}$ from the front of the cage. Centered in the panel was a $38-\mathrm{mm}$ hole. The measure recorded was the time required for the animal to put its head through the hole to the point at which both eyes were beyond the panel surface.

\section{RESULTS AND DISCUSSION}

The correlation between the two measures was .40; the correlation between the 12 strain means was .75. Particularly with respect to genetic variation, exploration of animate and of inanimate objects was closely related. For approach to humans, strain differences accounted for $18 \%$ of the total variance; for the physical object, it was $26 \%$. This indicates that, for purposes of experimental design in which exploration is a dependent variable, a useful gain in precision can be obtained by using genetically defined lines.

Table 1 shows the means and standard deviations by strain and sex within strain for each measure. INR, WAG, and TS3 were the most exploratory lines, and IR and MR/Har were the most inhibited. These would be the animals of preference for experimental designs in which control of exploratory response to unfamiliar objects is of importance.

An earlier study (Harrington, 1971a) examined emergence from a home cage into familiar and unfamiliar environments. The mean rank difference correlation of strain means for each sex between each of the 
Table 1

Latencies of Approach to Novel Objects of 12 Inbred Strains of Rats

\begin{tabular}{|c|c|c|c|c|c|c|c|c|}
\hline \multirow[b]{4}{*}{ Strain } & \multicolumn{8}{|c|}{ Approach Latencies in Seconds } \\
\hline & \multicolumn{4}{|c|}{ Animate Object } & \multicolumn{4}{|c|}{ Inanimate Object } \\
\hline & \multicolumn{2}{|c|}{ Males } & \multicolumn{2}{|c|}{ Females } & \multicolumn{2}{|c|}{ Males } & \multicolumn{2}{|c|}{ Females } \\
\hline & Mean & SD & Mean & SD & Mean & SD & Mean & SD \\
\hline $\mathrm{ACI} / \mathrm{Har}$ & 135 & 120 & 64 & 81 & 173 & 121 & 79 & 82 \\
\hline A990/Har & 68 & 102 & 75 & 113 & 89 & 110 & 68 & 84 \\
\hline A35322/Har & 111 & 116 & 51 & 83 & 103 & 93 & 53 & 37 \\
\hline F344/DuHar & 169 & 138 & 126 & 128 & 140 & 111 & 166 & 110 \\
\hline INR & 20 & 40 & 16 & 24 & 37 & 37 & 47 & 77 \\
\hline IR & 185 & 131 & 127 & 130 & 200 & 129 & 165 & 116 \\
\hline MNR/Har & 178 & 130 & 157 & 117 & 118 & 103 & 118 & 118 \\
\hline MNRA & 72 & 107 & 54 & 78 & 156 & 110 & 151 & 99 \\
\hline $\mathrm{MR} / \mathrm{Har}$ & 178 & 131 & 223 & 115 & 204 & 94 & 137 & 91 \\
\hline TS1 & 68 & 101 & 60 & 87 & 137 & 98 & 117 & 88 \\
\hline TS3 & 17 & 34 & 39 & 94 & 93 & 60 & 97 & 91 \\
\hline WAG/Har & 21 & 21 & 48 & 100 & 50 & 78 & 67 & 97 \\
\hline
\end{tabular}

Note $-N \geqslant 20$ for each sex within each strain.

present measures and each of those measures was $.76 \pm .10$. It would appear that all four measures measure much the same thing. If indeed the wild rat/ laboratory rat differences in response inhibition to novel objects represent a selection difference, then one would not expect such close genetic correlation between emergence and object approach measures, given polygenic factors. It is, of course, possible that the inhibition is a single-gene effect. Identification of such a single gene controlling a behavior of substantial evolutionary importance would be a significant scientific advance. Absence of the difference over a number of strains of widely differing origins would imply both a single gene and strong selection in the laboratory environment.

It has been observed that different measures of exploration may give very different results in comparing effects of social isolation (Einon \& Morgan, 1976). Lore and Levowitz (1966) noted that exploratory behavior of animals differentiated by prior social experience differed when measured by activity in an open field as compared with latency to emerge and explore from a small enclosure. Long latencies accompanied high activity. Comparing the present data with previous data on open-field exploration (Harrington, 1972), the reverse relationship was found. The strain means for latencies to explore novel objects from the home cage correlated -.43 with activity and exploration in the open field. Strains showing low latencies, that is, high exploration in emerging from home cage into strange or familiar environments and in approaching novel objects in the home cage, also showed high exploration or activity in the open field. Again, the measures were consistent. Whatever may be the differentiation mechanism influenced by social experience, it does not appear to be the same one tapped by genetic variation.
It seems more likely, therefore, that the wild-tame differentiation in response inhibition may reflect experience rather than selective breeding. The genetic variation would seem primarily to affect general exploratory tendencies. From a genetic and evolutionary perspective, neophilia and neophobia would appear to be opposites on a single dimension of exploratory behavior rather than independent variables.

\section{REFERENCES}

BarnetT, S. A. The rat: A study in behavior (Rev. ed.). Chicago: University of Chicago Press, 1975.

BillingSleA, F. Y. The relationship between emotionality, activity, curiosity, persistence and weight in the male rat. Journal of Comparative Psychology, 1940, 29, 315-325.

Billingsle A, F. Y. The relationship between emotionality and various other salients of behavior in the rat. Journal of Comparative Psychology, 1941, 31, 69-77.

BILLINGSLEA, F. Y. Intercorrelational analysis of certain behavior salients in the rat. Journal of Comparative Psychology, 1942, 34, 203-211.

Einon, D., \& Morgan, M. Habituation of object contact in socially-reared and isolated rats (Rattus norvegicus). Animal Behaviour, 1976, 24, 415-520.

Festing, M., \& StaAts, J. Standardized nomenclature for inbred strains of rats. Transplantation, 1973, 16, 221-245.

HaLl, C. S. The inheritance of emotionality. Sigma Xi Quarterly, 1938, 26, 17-27.

Harrington, G. M. Genetic-environmental interaction in "intelligence." I: Biometric genetic analysis of maze performance of Rattus norvegicus. Developmental Psychobiology, 1968, 1, 211-218.

Harrington, G. M. Strain differences among rats initiating exploration of differing environments. Psychonomic Science, 1971, 23, 348-349. (a)

Harrington, G. M. Strain differences in rotating wheel activity of the rat. Psychonomic Science, 1971, 23, 363-364. (b)

Harrington, G. M. Strain differences in open field behavior of the rat. Psychonomic Science, 1972, 27, 51-53.

Harrington, G. M. Strain differences in activity of the rat in a shuttle stabilimeter. Bulletin of the Psychonomic Society, 1979, 13, 149-150. (a)

Harrington, G. M. Strain differences in activity of the rat using a home cage stabilimeter. Bulletin of the Psychonomic Society, 1979, 13, 151-152. (b)

Harrington, G. M. Strain differences in free operant leverpress levels in the rat. Bulletin of the Psychonomic Society, 1979, 13, 153-154. (c)

Harrington, G. M. Strain differences in light-contingent barpress behavior of the rat. Bulletin of the Psychonomic Society, 1979, 13, 155-156. (d)

Harrington, G. M. Strain differences in open-field behavior of the rat. II. Bulletin of the Psychonomic Society, 1979, 13, 85-86. (e)

Harrington, G. M. Strain differences in passive avoidance conditioning in the rat. Bulletin of the Psychonomic Society, 1979, 13, 157-158. (f)

Harrington, G. M. Strain differences in runway learning in the rat. Bulletin of the Psychonomic Society, 1979, 13, 159-160. (g)

Harrington, G. M. Strain differences in shuttle avoidance conditioning in the rat. Bulletin of the Psychonomic Society, 1979, 13, 161-162. (h)

Harrington, G. M. Strain differences in simple operant barpress acquisition to an auditory stimulus by rats. Bulletin of the Psychonomic Society, 1979, 13, 163-164. (i) 
Harrington, G. M., \& Hellwig, L. R. Strain differences in basal metabolism of behaviorally defined rats. Bulletin of the Psychonomic Society, 1979, 13, 165-166. (a)

Harrington, G. M., \& Hellwig, L. R. Strain differences in organ weights of behaviorally defined rats. Bulletin of the Psychonomic Society, 1979, 13, 167-169. (b)

International Committe on Laboratory Animals. Defining the laboratory animal. Washington, D.C: National Academy of Sciences, 1971.
LoRe, R. K., \& Levowitz, A. Differential rearing and free versus forced exploration. Psychonomic Science, 1966, 5, 421-422. Small, W. S. Notes on the psychic development of the young white rat. American Journal of Psychology, 1899, 11, 80-100. Small, W. S. An experimental study of the mental processes of the rat. American Journal of Psychology, 1900, 11, 133-165.

(Received for publication September 21, 1979.) 